\title{
Mobile sourcing: A case study of journalistic norms and usage of chat apps
}

\section{Valerie Belair-Gagnon}

Hubbard School of Journalism and Mass Communication, University of Minnesota, USA

\section{Colin Agur}

Hubbard School of Journalism and Mass Communication, University of Minnesota, USA

\section{Nicholas Frisch}

Yale University, USA

\begin{abstract}
Since 201I, mobile chat apps have gained significant popularity worldwide and the leading chat apps have surpassed social networking sites in user numbers. These apps have become the hosts for everyday communication among a wide variety of users and, thanks to the functionalities of certain apps, have taken on new significance in reporting. Especially in Hong Kong (a high-income, high-tech society in which smartphones are in widespread use) and mainland China (an emerging market with more than I billion mobile phone users), journalists have turned to these apps to complement face-to-face interactions to gather news. Drawing on a case study building on in-depth interviews with foreign correspondents based in China and Hong Kong, this article discusses how journalists use chat apps and establish trust with their sources. This article explores journalistic sourcing on apps (e.g., encrypted or not encrypted; open or one-to-one communication), and seeks to understand individual and systemic levels of trust. It finds that there are differences of trust depending on the functionalities of individual chat apps, and that interactions in journalistic sourcing in face-to-face and online environments affect the generation and output of news stories. Chat apps allow reporters to use open or closed networks, and adopt one of several approaches: trust the network, master the network, or abandon the network. These findings suggest that chat apps
\end{abstract}

\section{Corresponding author:}

Valerie Belair-Gagnon, Hubbard School of Journalism and Mass Communication, University of Minnesota, 206 Church Street SE, Office 329, Minneapolis, Minnesota 55455, USA.

Email:vbg@umn.edu 
have an important role in communicating with sources, and should be a part of efforts to theorize journalistic sourcing.

\section{Keywords}

chat apps, China, foreign correspondents, Hong Kong, journalism, mobile media, sourcing, surveillance, trust

Mobile chat applications are software applications designed to operate on mobile electronic devices such as smartphones or tablets. Since 2011, numerous chat apps have emerged, including KakaoTalk, WhatsApp, Telegram, Snapchat, WeChat, Facebook Messenger, and LINE. These applications are part of information technology networks and the wider mobile and social ecosystem. Chat apps blend mass and interpersonal communication, including online and face-to-face interactions. Users can employ chat apps to create private interest groups, play games, transfer funds, or video chat with one or multiple individuals simultaneously.

As a result of their popularity and usage for political protests, chat apps have also been used by governments for surveillance purposes. In China, online communities have discussed the dangers of using chat apps for citizen mobilization (Lam, 2009), as many websites are subject to censorship, regulation, and surveillance (Crandall et al., 2013). Chinese authorities have pressed the corporate leadership behind apps like WeChat to censor users in China, and filter content-related keywords on a wide variety of platforms (e.g., terms relating to the June 4, 1989 crackdown on Tiananmen Square).

While chat apps have become important channels for government surveillance, they also offer ways for people who may be surveilled to circumvent such practices. Savvy app users have found ways to circumvent this censorship, such as modifying keywords when communicating with each other about controversial issues (Hardy, 2013). Chat apps have become the venues for much of this countersurveillance activity, raising questions of how journalists use chat apps to source stories and how these reporters build trust with their sources.

Mobile chat apps have also been useful tools for local and foreign journalists seeking sources and developing trust in relationships with these sources for a wide variety of news stories. This trend represents a stark departure from the early skepticism by legacy news toward the use of mobile media (Westlund, 2013). In the past years, a burgeoning industry literature has outlined how reporters can use chat apps (e.g., Crete-Nishihata, 2015; Lee \& Ho, 2014; Rai, 2014; Silverman, 2014). In recent years, chat apps have been especially prominent in journalism in Hong Kong and China, and have been put to widespread use by news organizations, reporting teams, and solo reporters (Belair-Gagnon, Agur, \& Frisch, 2016).

This article is the result of a study of journalistic sourcing using chat apps, focusing on a case study of Western foreign correspondents using chat apps in contexts of surveillance in Hong Kong and China. This case illustrates why foreign correspondents use chat apps to communicate with sources: because this is where sources can most easily be 
found, and because chat apps offer more discreet means of communication than open platforms such as Twitter.

\section{Case study}

Hong Kong and mainland China offer several advantages for a case study of journalistic usage of mobile chat apps. First, the region is a geographical, technological, and social context in which chat apps have been put to extensive use but not widely researched in journalism studies. The context of mainland China and Hong Kong allows researchers to answer questions about the role of chat apps in journalistic sourcing. By focusing on these two sites of analysis, this article showcases a region in which mobile phones are the most popular means of accessing the Internet, and chat apps the most popular method of user-to-user communication (Belair-Gagnon, Frisch \& Agur, 2017).

The leading chat apps in our study (e.g., WhatsApp in Hong Kong and WeChat in mainland China) are ubiquitous and play essential roles in all facets of social life. These include everyday online interactions with a wide range of individuals such as coworkers, activists, friends, and family members (Belair-Gagnon et al., 2016). This paper also allows us to understand journalistic epistemology by exploring interactions between journalists and sources on these apps. By studying how reporters use chat apps to communicate with their sources and build trust with them, this case study identifies implications for news production processes and norms.

This paper therefore has two areas of inquiry: (a) how journalists source on chat apps and (b) how in interactions between sources and journalists on chat apps, journalists socially construct trust with their sources. For this reason, the following literature review focuses on journalistic sourcing, mobile sourcing, and trust, in that order. We contribute to the literature on sourcing by showing that journalists construct trust using the medium (chat apps), and that journalists navigate swiftly through different types of trust building with sources. This research has theoretical implications for how we conceptualize journalistic sourcing and journalistic trust-seeking with sources in mobile contexts, and why these patterns of journalistic use are visible.

\section{Sourcing and news production}

This paper explores journalistic sourcing in news production because these interactions shape the ways that news stories are produced and focused on (Sigal, 1973). These online, offline, and hybrid social interactions in sourcing are important since, as Ettema and Glasser (1998) argued, journalists must constantly make news judgments and moral judgments by negotiating what they think is important to cover and what they think their audience will find interesting. The rich research on journalistic sourcing has shown that journalists rely mostly on power elites or official voices during the process of newsgathering (Gans, 1979). However, recent research has found that in news discovery and production processes, citizen and mainstream news websites tend to rely more on unofficial sources (Reich, 2008b), and alternative journalists tend to privilege nonofficial sources more (as opposed to official sources such as policy-makers, the police, or the government; Atton \& Wickenden, 2005). 
Given the importance of communication technology to journalistic sourcing, this paper explores the ways that chat apps serve as an information system, and can thus shape sourcing norms and practices. As Lewis and Westlund (2014) wrote, it is increasingly important to explore how the social, cultural, and technological qualities of big data affect the interactive nature of sourcing. Building on the question raised by Lewis and Westlund (2014), we argue that it is important to reflect on how trust manifests itself in and through journalistic sourcing, using a case of journalistic use of chat apps in a particular political, social, and cultural context.

\section{Mobile sourcing}

By focusing on mobile chat applications, ours is a study on mobile communication, in contrast to studies of social media such as Twitter, which are online but not uniquely mobile. While some chat apps have desktop browser-based messaging options (e.g., Google Hangouts or LINE), this is secondary for most users. These apps are mobile first and, compared to other social networking platforms, often connect larger numbers of users and enjoy higher user retention. Chat apps are essential to foreign correspondents because of the primacy of mobile devices as tools for Internet access in most parts of the world, and because of the growing number of digital native users. Because a large number of people across East Asia communicate on chat apps, reporters increasingly use these apps to locate, assess, and communicate with sources.

For journalists covering stories in China and Hong Kong, chat apps are essential sites for newsgathering. They build on the capabilities and ubiquity of mobile devices, and enhance reporters' abilities in newsgathering. Chat apps allow users to exchange multimedia information with others in real time using tools such as text messaging, voice messaging, and file sharing. As Westlund noted, "mobile devices have enhanced the possibilities for journalists to work and report from the field. They can be used for news reporting for mobile news platforms but also for the entire cross-media portfolio" (2013, p. 13).

Foreign correspondents have been especially avid users not only of mobile communication, but also of chat apps, which have been part of their way into the societies they cover. As opposed to local correspondents, foreign correspondents often find themselves in a position that requires more trust-building, and they are less bound to the place they cover than local reporters. Chat apps allow foreign reporters a shortcut to building their networks: they can dive into communities of interest and, in the process, quickly understand the context of events, find reliable sources, and verify facts. These mobile applications can thus be sites of new forms of social interaction between foreign correspondents and sources (Belair-Gagnon, Agur, \& Frisch, 2017).

In recent years, the expansion of mobile telephony and declining cost of service have made chat apps highly popular and, in many places, more popular than social networking sites such as Facebook or Twitter. Journalistic sourcing with mobile media is an emerging area of academic inquiry. Researchers have explored how sources use chat apps to reach out to journalists and provide them with information without being physically present at the scene. Chat apps have allowed journalists to report more quickly from remote areas with limited cellular connectivity. For instance, journalists have sourced 
news by subscribing to NGOs' contact lists and chat apps alerts, and through anonymous tips or eyewitness sources on topics of interest such as human rights violations, to investigate the story before official sources control the narrative (Mabweazara, 2011).

Compared to social networking sites, chat apps offer journalists enhanced privacy for communicating with sources, thanks to encryption. Cooper (2007) found that digital sourcing practices (e.g., on mobile devices) offer a potentially new and wider set of sources for journalists, and reduce their dependency on institutional sources. While chat apps provide opportunities for journalists to report on otherwise inaccessible stories, these apps pose challenges in contexts of surveillance. In addition to creating new host sites for interactions between journalists and sources, chat apps have emerged as ways for reporters to build trust with sources via these apps.

Using the work of early newsroom ethnographies (Breed, 1955; Tuchman, 1972) as background, scholars have analyzed the social construction of mobile media and the resulting impact on everyday news routines (Mabweazara, 2011; Westlund, 2010). For journalists and news organizations covering crises, mobile media have ushered in a new set of practices in newsgathering (Lorenzo-Dus \& Bryan, 2011). With the arrival of location-based services and interactive maps, for example, mobile media have allowed for a new locative journalism (Nyre, 2012) and for newsroom managers to work remotely (Väätäja \& Egglestone, 2012). Smartphones have allowed for cross-platform news production (Mills, Egglestone, Rashid, \& Väätäjä, 2012) and for mobile news distribution (Westlund, 2013). These new features of news production have led to a new set of business practices for news organizations that make effective use of mobile technology (Büren, 2011; Nel \& Westlund, 2012). In this way, mobile technology has been at the forefront of recent changes in practices in news production. But as Westlund points out, "reluctant to relinquish their historical authority and control, the long-established ideologies and practices of legacy news media continue to guide their approaches to participation" (2013, p. 19). This article will thus examine (a) the practice of journalistic sourcing and (b) how sourcing takes place on different chat apps, taking into account the technical capabilities and features of these apps.

\section{Trust as a norm}

Because trust is a core principle of journalism (McBride \& Rosenstiel, 2014), it is important to explore the ways that journalists communicate and gain sources' trust via chat apps. ${ }^{1}$ Our case study also explores how journalists socially construct trust with sources via open (e.g., WeChat) and closed (e.g., Telegram) chat apps. As a way to understand how journalists seek to build trust with their sources via chat apps, this article uses the concept of social construction of trust.

The concept of trust has been examined in several academic disciplines, including psychology, sociology, anthropology, economics, and information systems (Dickinger, 2011). Sociologists have distinguished among cognitive, emotional, and behavioral analytical dimensions of trust. They suggest that trust undergirds our everyday lives and is a social construct, and that these three dimensions are interlinked (J. D. Lewis \& Weigert, 1985; Weigert, 1981, p. 982). As Weigert puts it, "trust . . is a pure social construction which answers to our need for security by seeming to be a fact when it is always a projected assumption" (Weigert, 1981, p. 982). 
Scholars have distinguished between individual trust (e.g., in which a source trusts a journalist not to betray their confidence) and systemic trust (e.g., in which a source trusts a particular technology or set of institutional procedures designed to protect sources), and found links between these two broad categories. This literature raises two questions in the context of chat apps: How do journalists build trust with sources via chat apps? And how does this usage follow or differ from the ways scholars have conceptualized offline trust building?

Salo and Karjaluoto (2007) argued that trust is a key component of online interactions. And Dickinger (2011) found that there are differences of trust depending on the online information channel. Dickinger indicates that there are significant differences between level of trust in user-generated content channels by linking trust to the "perception of ability and integrity regarding the customers that generate content" (2011, p. 387). ${ }^{2}$ Building from this literature on individual and systemic trust, this paper looks at how journalists build trust with sources in everyday life interactions on chat apps by using a case study approach.

This paper contributes to journalism studies and the field of media and communication. Our contribution to the literature on trust is that we use the social construction of trust to discuss mobile journalistic sourcing. The literature on trust thus helps us to explore social interactions in journalistic sourcing via mobile chat apps. This literature also allows us to analyze how journalists socially construct the norm of trust with their sources via these apps. The main contribution of this paper is not to the theory of trust building on chat apps; instead, we contribute to the study of journalistic sourcing practices on chat apps, within the larger context of mediated communication between journalists and sources, with mobile phone communication as the predecessor. We focus on sourcing in contexts of surveillance because reporters and sources often use chat apps with the intention of evading the surveillance that would have monitored their activity on social networking sites like Facebook or Twitter. The literature on trust is thus a vehicle that allows us to discuss mobile sourcing. To study mobile sourcing and the social construction of trust in journalistic sourcing via chat apps, this paper asks:

RQ1: How do journalists use mobile chat apps for sourcing in contexts of surveillance?

RQ2: How do journalists build trust with their sources via chat apps?

These questions allow us to reflect on the ways that chat apps affect the interactive nature of sourcing. This paper also discusses the multiplicity and complexity of journalistic sourcing on chat apps. Using the literature on sourcing and trust, this article's conceptual framework considers journalistic sourcing on apps (e.g., encrypted or not encrypted; open or one-to-one communication), and explores individual and systemic levels of trust. We hypothesize that there will be differences of trust depending on the functionalities of individual chat apps, and that interactions in journalistic sourcing in face-to-face and online environments will affect the generation and output of news stories.

\section{Methodology}

This paper's case study explores how foreign correspondents based in Hong Kong and mainland China communicate with sources on chat apps in contexts of surveillance, and 
how they build trust with their sources in a mobile context. Given its importance as a major Asia hub for large news organizations such as Bloomberg News and the International New York Times, Hong Kong is key to understanding leading organizational practices in global media. Mainland China hosts a large number of international news organizations' bureaux and stringers, particularly in Beijing and Shanghai. However, news organizations such as the International New York Times and Bloomberg News have faced pressure as the Chinese government has threatened to revoke journalists' work visas (Magistad, 2013). And although Hong Kong's Basic Law guarantees press freedom and there is negligible direct censorship in Hong Kong, surveillance is widespread (Belair-Gagnon et al., 2016).

To explore the changing interactions between journalists and sources, from June 2015 to March 2016, we conducted 34 in-depth semistructured interviews with foreign correspondents based in Hong Kong and China. We began by soliciting interviews from reporters who had covered the 2014 Umbrella Movement protests, and reached out to other journalists in foreign correspondents' communities using word-of-mouth connections. These protests, possible in the semiautonomous enclave of Hong Kong but highly sensitive in neighboring mainland China, were for months a focal point of global media reporting and Chinese government surveillance. These moments of political unrest provided us with an information-rich series of events covered by the foreign correspondents we interviewed. By speaking to these reporters, we sought to understand their experiences covering political unrest in the context of online government surveillance.

On average, our interviews lasted 60 minutes and focused on the ways journalists used chat apps to communicate with sources. To ensure a diversity of respondents, our sample included a range of different journalists' backgrounds: 15 women, 19 men, from print newspapers and their digital editions, print magazines and their digital editions, digital-first sites, wire services, and broadcast services (television and radio). During these interviews, journalists repeatedly mentioned how they used chat apps in contexts of surveillance. We coded the interviews by reading them and tagging segments of interest related to journalistic sourcing and surveillance. Considering the range of journalistic practices, we developed a thematic code of how journalists build trust with sources.

\section{Findings}

Journalists today have multiple ways of interacting with sources. Surveillance and the dynamics of sourcing on chat apps create difficulties in building trust. This section discusses how journalists used chat apps for sourcing (RQ1). It then explores how, from foreign correspondents' perspectives, journalists developed trust with sources (RQ2). We distinguish between closed apps (e.g., encrypted Telegram and WhatsApp private groups) and open platforms (e.g., WeChat public feeds). The paper's findings highlight how interactions in journalistic sourcing in hybrid face-to-face and online environments via chat apps affect the generation and output of news stories.

\section{Journalistic sourcing practices on chat apps}

Communication technology has long played a significant role in journalistic sourcing. New technology has allowed journalists and sources to communicate quickly, across greater 
distances, and at a lower cost, and has facilitated richer journalistic sourcing (Reich, 2008a). Chat apps have increased the volume and granularity of breaking news information that can be gathered and sent instantly by reporters, much like the teletype and fax machine increased the information density and speed of a single news transmission from a correspondent in the field filing a story. The journalists we interviewed use chat apps primarily to target audiences and segments of interest, keep a pulse on ongoing news stories, organize interviews with people to meet face-to-face, and circumvent surveillance.

For journalists trying to understand and report on fast-moving events, chat apps have become versatile, scalable, and information-rich sourcing tools. Among reporters, there was a sense that chat apps have developed a culture of rapid replies, informal communication, and short bursts of conversation among participants. In their communication with sources, reporters made use of chat apps' features: sharing multimedia files; access to websites; and personal, group, and mass communication. Reporters also made decisions about how public or private the conversation should be, depending on the sensitivity of the topic and the technical savvy of participants in the discussion.

Reporters claimed that they use chat apps to communicate with sources when either they or the sources need a quick answer. In addition to creating opportunities to engage audiences, chat apps have allowed journalists to target audiences by segment of interest. A wire service journalist noted: "I mainly followed local Hong Kong people and then I followed a few things like [a local Hong Kong Reddit-style message board], [a group of teenage student activists], and [an older group of academics]." Seeking to get their message to media outlets, tech-savvy activist groups included reporters in chat groups intended for journalists. These functioned as ongoing digital press conferences, and often served as groups' primary venues for press interactions with newsmakers including receiving press releases and posing questions (Belair-Gagnon, Agur and Frisch, 2017).

While chat apps allowed reporters to keep a pulse on ongoing news stories or sort out interviews with people they had met face-to-face, they mentioned the challenges of using these apps in a surveillance context. For example, some social movement leaders may be tempted to abandon a particular chat app or use more secure means of communication. Reflecting on how reporters need to keep their sources safe from harm, a correspondent confided:

What has changed is a growing awareness that social media [and chat apps] could get you in trouble. Now they are in these [chat apps] groups so they need to get access to these groups. Now slowly there is a movement away from these [chat apps] groups and platforms that could be easily infiltrated, spied on, to secure apps.

As the 2014 Umbrella Movement protests grew in size and chat apps became targets of hacking, activists crowdsourced solutions for security problems. Thus emerged a catand-mouse game in which users of chat apps tried to stay ahead of efforts to disable or degrade chat apps as communication tools. This showed how, to follow their sources, reporters had to quickly shift from one app (with one set of technical features) to another. As one social media savvy reporter said:

[One student group] was getting hacked all the time. [A group leader] would often post a screen grab of a message that says someone has tried to enter your account or something. It tells you 
when someone's tried to access your account. Then I would see him ask people in the hacking community [prodemocracy tech activists], "Can someone help me see what's happened?"

In light of those challenges, journalists we spoke to tried to maintain trust with sources while managing the technical capabilities of these mobile apps. An important finding of this research (RQ2) is the existence of two nonexclusive and fluid trends in sourcing: sourcing using open and closed apps.

\section{Sourcing on closed networks}

This section defines trust in these contexts and highlights differences in journalistic trust building across closed and open networks. It discusses how reporters socially construct trust using journalistic practices, working with sources' knowledge of the technology on closed and open networks. For instance, as illustrated earlier, when reflecting on trust in journalistic sourcing in the context of surveillance, journalists mentioned that source protection is a perennial concern and chat apps present a new type of communicative space for an old problem. While individual chat apps differ from each other and continue to evolve in the features they offer, they are distinct in their efforts to create closed spaces for participants to communicate.

One of the important features distinguishing mobile chat apps from social networking sites is the partly closed nature of communication among parties. Chat apps allow for different types of conversation, from many-to-many (potentially involving hundreds of participants), some-to-some (involving smaller groups, with participants likely to know each other offline), to one-to-one (the most common for journalistic sourcing). In each case, participants need to be added to a discussion by a group member.

Another feature of closed chat apps is encryption. Some closed apps (e.g., Signal or Telegram) came into existence as encrypted apps for individuals who need private communication. Others (e.g., WhatsApp) have added encryption capabilities after several years of existence, and in response to user demand. This feature reflects the closed or open nature of communication on different chat apps.

While sourcing on open platforms is common among foreign correspondents, the journalists we interviewed said that since the 2014 protests there has been an increase in sourcing using closed apps. It is unclear whether this increase in usage is the result of increases in apps' capabilities, especially concerning security (e.g., WhatsApp became encrypted in 2016) or increased trust in these apps by journalists and sources.

In this latter type of sourcing, journalists source confidentially, for example by using encrypted messaging applications. When encryption is not possible, reporters have made effective use of unencrypted channels. A journalist said:

Among activists, there is quite an open data movement. It is very geeky. Like the activists before [the 2014 protests] were just a group of geeks. They were into open data and then someone in the mainland created this app that was actually a fake app that pulls user information. Then, I think people slowly moved to Telegram because of surveillance.

To communicate in private with sources, many journalists have used the encrypted app Telegram, as a digital reporter said: 
A lot of people said, "Get it, it's really secure." We respond, "Okay how is this secure?" and they say, "Well no one ever been able to hack it." It just didn't seem that convincing. Then I got it and immediately I got three requests.

Unlike other social networking sites such as Twitter, chat apps offer different ways of sourcing through software features that allow for "precise" and "scaled" sourcing, as a reporter mentioned.

An investigative reporter remarked that once journalists move into this semiprivate social space, they then transition into a traditional journalist-source relationship:

A lot of the information you get to kind of start off the reporting process is derived from people posting anonymously on these forms and things like that, and so the way you contact them is to send a private message to them and say "hey, I'd love to talk to you," or say, you reply to them in the forum and say "hey, can you talk to me?" Then somebody will say, "here's my QQ, just message me." More likely the other option is if we're reaching out to them we'll say, "I want to talk to you, here is my QQ, can you contact me?"

To protect sources and data, journalists tried to take conversations offline (e.g., by meeting in person) or to an encrypted channel (e.g., Telegram). In contrast, reporters mentioned that these moves (especially the latter) can have the undesired outcome of making the source nervous or reducing the source's willingness to continue the conversation, especially about sensitive subjects. An editor remarked:

You see a post that is interesting or a post on WeChat and you contact the person and then suggest an alternative way of communicating ... "let's talk this is my phone number, let's talk on Telegram." The problem is you never really know what kind of literacy they have in using the tools. Some people want to make a case but they don't want to use them [afraid that the authorities would be monitoring them] they have nothing to hide. [Sometimes] it is probably safer for everyone to just be open about it to talk over chat. There is also an intentional transparency that you have. It is something that I don't really like but if it works, that is another option if you've nothing to hide.

In these cases, journalists felt a heightened professional responsibility to keep their sources secure. To some less sophisticated sources, the mere mention of encrypted channels seemed like an escalation that resulted in them losing trust in the journalist or holding back information. In such situations, the availability of more secure channels did not foster the trust that journalists had hoped for; instead, this heightened security served as a reminder to sources of the risks of being surveilled.

For sources with low technical skills, encrypted channels seemed to involve onerous work. They might need to download and install additional software, purchase new hardware, learn how to use a new interface, and invest considerable time and effort in the process. A social media savvy reporter similarly confided:

I stopped using WeChat and removed it from my phone and to this day I still haven't redownloaded WeChat. I just don't feel comfortable knowing I could endanger the people that I speak to, I don't want to have anyone connected to me [to be in danger], especially because I have a lot of mainland friends who are on it [on WeChat]. 
Groups are moving away from chat apps to more secure sites, but tech savvy sources feel less trusting when reporters ask them to go on to secure sites, and see this as a distressing "escalation." In this context, by abandoning particular chat apps, journalists exercised their professional discretion in choosing what might be more secure for their sources. To conduct news sourcing on closed networks, journalists developed practices to build trust with sources (e.g., keeping sources secure by moving offline or consulting sources on what mode of communication they preferred). While journalists mentioned that they used closed platforms, open platforms were also important, particularly for reporting in mainland China.

\section{Sourcing on open networks}

The journalists we interviewed remarked that they practiced open sourcing when covering protest movements, which reflects a tendency toward public trust in journalists. This section explores how journalists use open chat apps as part of their sourcing in this context.

A digital news journalist remarked that many of his and his peers' conversations begin in open chat rooms or web boards and progress to closed spaces in chat apps. Comparing chat apps to emails in their usefulness, a reporter told us: "You kind of know there's an end to the story because [people] were all connected. It was great to have that method of information [chat apps]. I don't think email would have been as helpful [as chat apps]." Another reporter said: "Sometimes [the group] will say, 'Hey guys press conference at 1 a.m. outside the government offices' or, 'Hey, here is a statement,' and they will paste an entire statement on the chat app. Somebody might say, 'English, please." Yet in communicating with sources, reporters discussed the ways they moved from open networks (including websites, social media, or open chat apps, which are not secure and are commonly surveilled by government agencies) to closed or semiclosed chat apps. This movement from open to closed spaces suggests that reporters and sources negotiate different levels of trust depending on the online context.

When journalists and sources trust the system, their relationship resembles what Lewis and Usher (2013) referred to as people hiding in plain sight. Many sources preferred a low-key public presence to secrecy. Hiding in plain sight on these open platforms involved multiple practices. Unlike public-facing platforms like Weibo, chat apps allow for more discretion and gradations of exposure by journalists and sources. The Chinese government heavily monitors and censors Internet discourse regarding evolving news events, and public social media accounts can become a political and legal liability for individuals who run them. Chat apps offer a more discreet means of communicating with sources without drawing unwanted attention from authorities.

For sensitive topics or for individuals already under surveillance, chat apps cannot automatically be considered secure. Chat apps developed by China-based companies often offer automatic and warrantless backdoor access to authorities. For example, journalists and other chat apps users utilize codes to obscure messages on chat apps, for instance by misspelling words. In English, journalists and activists could write "Tibt" instead of "Tibet," a ruse that would not fool a dedicated eavesdropper already monitoring the conversation, but makes an individual message less likely to be automatically flagged by surveillance filters. 
Importantly, hiding in plain sight is not just for sources, journalists do it too. To protect their sources, they adopt the same low-key communicative style (e.g., using codes when writing) as the sources they are pursuing. At some point, either the source or the journalist might suggest that they move the conversation to someplace more discreet. During the period when the contact happens in plain sight (on an open platform), the source and journalist are assessing each other's intentions and motivations, and deciding to what extent they can trust each other.

In an example of this practice, a reporter discussed the importance of making connections on WeChat when dealing with sensitive material, assuming that communication would be funneled through the surveillance tools of the Chinese government:

If I'm going to be making new connections on WeChat with sources and especially when I'm dealing with sensitive material, I try and stay vague or low key. I know that WeChat has links to the [Chinese government's] party, I assume that all of my communications on WeChat are being funneled through the Chinese government's equivalent of PRISM, and if I feel like any of my conversations on that site might potentially endanger any of my sources, I tend, I try to err on the side of caution.

In interviews, journalists highlighted that certain sources wanted to keep the conversation open to surveillance to demonstrate to the authorities that, despite their conversations with foreign journalists, they were not engaging in significant subversion against the government. By remaining in the open, participants seemed to believe that they were marking themselves as "working within the system" and decreasing the likelihood that they would have problems with the government.

Other journalists decided not to use chat apps to communicate with their sources, or simply rejected the use of chat apps. Reflecting this trend, a wire service journalist warned us not to add someone on WeChat if doing so might get them in trouble. The reporter said:

I'm pretty careful about this. I know many journalists that are not that careful about this. I am very aware of the fact that like the worst that's going to happen to me is I'll get deported and the worst that's going to happen to them is much worse.

Journalists mentioned that if a conversation was progressing well, they were reluctant to shift to an encrypted channel. In doing so, journalists could enjoy the short-term gain of continuing a fruitful discussion. But this could increase the source's exposure to surveillance. This usually depended on whether the journalist or the source was already a target of surveillance by authorities. An American reporter based in China narrated that he attended a trial in which a prominent dissident was sentenced for causing disturbances. During the trial, supporters of the dissident gathered in front of the courthouse with journalists, diplomats, and state security. The journalist recalled that,

We all got pushed around, shuffled away from the steps outside of the courthouse. There were a few observers and supporters of [the dissident] in that crowd and I spoke with them. I got their contact information. I added a couple on WeChat and then I left the scene to go write it up, and yet, the . . . police presence outside of the courthouse didn't die down. . . . The people I had 
added on WeChat at the scene were sending me photos and videos of these scuffles after the fact so I got a really good sense of what was going on after I left, and it was valuable to my reporting.

This practice reflected the increasing multimediality and citizen-driven aspects of mobile communication in journalism. Based on these results, the following section will discuss how journalists build trust in their interactions with sources. As Dickinger (2011) found in a study of different levels of trust on online information channels, our results suggest that journalists must navigate swiftly through different chat apps, understand their different capabilities and limitations, and deploy different forms of trust-building with sources.

\section{Discussion}

Building on studies of journalistic sourcing, mobile sourcing and social construction of trust in journalism, our results show that by sourcing via chat apps, reporters have been able to fill in details, find eyewitness accounts and insider perspectives, and quickly gain journalistic expertise while meeting a deadline. These developments echo findings from early mobile journalism studies (e.g., Westlund, 2013). In our interviews, journalists also suggested that chat apps allowed them and their sources to communicate more quickly, across greater distances, and at a lower cost (e.g., Cooper, 2007; Mabweazara, 2011; Reich, 2008a).

This paper has identified how reporters socially construct trust in sourcing on open and closed networks. Building on our theoretical framework, we found that foreign correspondents follow established norms (e.g., confidentiality and safety of sources) and practices (e.g., building systemic or individual trust). For example, reporters talked about the importance of mastering chat apps' technological features such as encryption due to pressure from news organizations to follow a journalistic code of online conduct. A European journalist said:

My company requires that my phone is encrypted. My computer is also encrypted. I wouldn't know about the technicalities because my techy friend helped me set both things up. Sometimes I use encrypted email, but I haven't had much success in trying to get any of my sources to use it. (Interview, 2016)

In developing trust with their sources, journalists also articulated that they had a responsibility to keep their sources safe and develop practices such as "adding a person on chat apps only if you are confident it will not get them in trouble." Overall, similar to the literature on mobile phone use in journalism, journalists used chat apps and interacted with sources on these apps based on their understanding of newsroom policy (e.g., whether they had to use an encrypted channel), professional authority (e.g., keeping sources safe), devices (e.g., smartphone vs. Blackberry), mobile applications (e.g., WeChat vs. Telegraph), and Internet features and capabilities (e.g., adding hyperlinks or multimedia sources on chat apps).

These new practices require that journalists navigate a complex and rapidly changing set of online spaces when sourcing for stories. Depending on the context, journalists must develop different levels of trust with their sources; this is related to technical 
features and norms of chat apps. Importantly, journalists and sources negotiate trust in the system (the technology) and trust in the individual (the source or the journalist). Since a trusting relationship with sources is central to the newsgathering process, these are important findings that highlight how reporters need to navigate multiple contexts in mobile environments.

Chat apps also allowed reporters to first use open or closed networks and choose one of several approaches. They could trust the network, typically by using closed network and encrypted applications such as Telegram and WhatsApp. Reporters also sought to master the network to be more trustworthy to the source. And reporters could also abandon the network for being untrustworthy. In these cases, the level of source-journalist trust in the system is at its lowest. For example, a reporter said,

I did a story and I didn't have WeChat, I didn't have anybody. Some of the people were quite young and were like "add my WeChat," and I was like "oh sorry I don't have it." I would love to have this relationship with these [people] and talk to them over a long period of time. I think it would be really fascinating. I don't really think it's right for me to accept theirs. I don't think they'd fully understand this, that they would be [compromised by the government].

This reporter's observations lead us to another point: that patterns of mobile sourcing on chat apps are visible in large part because of their features (they are multimedia, instant social networks; in short, they are fun) and because of apps' extensive geographic presence (e.g., WhatsApp in Hong Kong, WeChat in mainland China, KakaoTalk in Korea, and LINE in Japan and Taiwan). In the span of a few years, chat apps have become the default method of communication in all sort of social situations. For reporters seeking initial contact or a follow-up from a source, "do you have WhatsApp?" is a benign question with an almost certain answer: "yes." Chat apps provide a sourcing context that is entertaining yet encrypted, and performative yet private.

By examining how reporters use chat apps for sourcing, our case study has shown that the interactional nature of journalistic sourcing is complex and multifaceted on mobile chat applications. There was a significant difference in how journalists sought to build trust across chat apps. This suggests a dual importance: The technological features of chat apps create a set of communicative possibilities for mobile sourcing; and given the variety and complexity of online communicative spaces, mobile sourcing also depends on social factors, including how journalists and sources understand norms and best practices on chat apps in contexts of surveillance.

\section{Conclusion}

This article has examined interactions between journalists and sources on mobile chat applications using a case study of foreign correspondents communicating with sources in contexts of surveillance. On the one hand, this empirical case study makes the research potentially less generalizable (e.g., in the US, journalists may use Snapchat more than the apps we discussed in this paper, and in the UK, according to a set of experiments conducted by the $\mathrm{BBC}$, the processes and outcomes may differ from those we observed in our research. On the other hand, our approach offers a conceptual and methodological 
foundation for future studies, which could use interviews and a case study approach to research different chat apps in different parts of the world.

More broadly, this study has implications for how we conceptualize journalistic interactions with sources on chat apps focusing on both trust in the individual and trust in the system. This article also identifies the ways that the technical features of mobile chat applications create opportunities and challenges for journalists seeking to build trust with their sources. To keep their sources safe, journalists will need to use their discretion when using chat apps to report on sensitive issues.

Our study offers a new context for scholars to understand journalistic trust-building with sources. Several studies of mobile and social media news production suggest that journalistic norms (e.g., trust or objectivity) are socially constructed. This literature shows that journalists negotiate norms by taking into consideration professional practices and norms, as well as technological and cultural contexts (e.g., Belair-Gagnon, Agur and Frisch, 2017; Hermida, 2010; Westlund, 2013). While this line of argument reflected foreign correspondents' sourcing practices, we found that reporters had to constantly shift from individual- to system-level trust. As a result, the mobility and scalability aspects of chat apps offer different ways of sourcing and gaining trust from sources. At the same time, foreign correspondents suggested that chat apps can foster a form of "armchair journalism" that limits reporters' ability to find accurate and meaningful stories in the field.

As these apps and networks continue to develop (in terms of being available on more devices, connected to more information, and in the dimension of their social networks), there is an opportunity for sustained qualitative work that explores the evolution of journalistic uses of chat apps in different social and political contexts. Such work would provide scholars and practitioners a deeper understanding of the scope and nature of interactions between journalists and sources on mobile chat apps. And with more empirical studies in a wider set of contexts, scholars would have the opportunity to reflect on the broad theoretical significance of chat apps, both for journalism studies and for mobile communication.

\section{Funding}

This work was supported in part by the John S. and James L. Knight Foundation and the Tow Center for Digital Journalism at Columbia University.

\section{Notes}

1. In much the same way that Twitter and Facebook allowed for a new type of "social journalism" (Hermida, 2012), we see chat apps as an extension of the trend toward a more conversational newsgathering process. And just as social media channels have enhanced beat reporting during elections (Broersma \& Graham, 2012) or crisis reporting (Belair-Gagnon, 2015; Mäkinen \& Kuira, 2008), so too are chat apps now sites of reporting that demand journalistic attention and expertise in language and local context. These studies show the significance of journalistic practices using social media in different contexts and provide starting points for analysis of mobile sourcing on chat apps.

2. These questions of trust are linked to the broader concept of social construction in news production (e.g., Hall, Critcher, Jefferson, Clarke, \& Roberts, 2000; Schudson, 1997). With the 
arrival of online journalism, scholars have examined the ways that open participation exists in tension with journalists' efforts to maintain professional boundaries (Lewis, 2012). More broadly, studies of mobile technology have identified new patterns in professional and social interactions (Ling \& Campbell, 2011), such as allowing users access to information flows and communication while carrying out their daily activities (Campbell, 2013).

\section{References}

Atton, C., \& Wickenden, E. (2005). Sourcing routines and representation in alternative journalism: A case study approach. Journalism Studies, 6(3), 347-359.

Belair-Gagnon, V. (2015). Social media at BBC News. London: Routledge.

Belair-Gagnon, V., Agur, C., \& Frisch, N. (2016). New frontiers in newsgathering: A case study of foreign correspondents using chat apps to cover political unrest. New York, NY: Tow Center for Digital Journalism, Columbia University.

Belair-Gagnon, V., Agur, C., \& Frisch, N. (2017). The changing physical and social environment of newsgathering: A case study of foreign correspondents using chat apps during unrest. Social Media + Society, 3(1). doi:10.1177/2056305117701163

Breed, W. (1955). Social control in the newsroom. Social Forces, 33, 326-333.

Broersma, M., \& Graham, T. (2012). Social media as beat. Journalism Practice, 6(3), 403-419.

Büren, K. (2011). Mobile media services at sub-Saharan African newspapers. Paris, France: The World Association of Newspapers; the African Media Initiative.

Campbell, S. W. (2013). Mobile media and communication: A new field or just a new journal? Mobile Media \& Communication, 1(1), 8-13.

Cooper, G. (2007). From their own correspondent? New media and the changes in disaster coverage: Lessons to be learnt. Retrieved from https://reutersinstitute.politics.ox.ac.uk/sites/ default/files/From\%20Their\%20Own\%20Correspondent_0.pdf

Crandall, J., Crete-Nishihata, M., Knockel, J., McKune, S., Senft, A., Tseng, D., \& Wiseman, G. (2013). Chat program censorship. First Monday, 18(7). doi:10.5210/fm.v18i7.4628

Crete-Nishihata, M. (2015). Asia chats: Analyzing security and privacy of mobile messaging apps. Retrieved from https://jmsc.hku.hk/2015/03/asia-chats-analyzing-security-and-privacy-ofmobile-messaging-apps

Dickinger, A. (2011). The trustworthiness of online channels for experience- and goal-directed search tasks. Journal of Travel Research, 50, 378-391.

Ettema, J. S., \& Glasser, T. L. (1998). Custodians of conscience. New York, NY: Columbia University Press.

Gans, H. (1979). Deciding what's news. Evanston, IL: Northwestern University Press.

Hall, S., Critcher, C., Jefferson, T., Clarke, J., \& Roberts, B. (2000). The social production of news.In P. Marris \& S. Thornham (Eds.), Media studies: A reader (pp. 645-652). New York, NY: New York University Press.

Hardy, S. (2013). Asia chats investigating regionally-based keyword censorship in LINE. Retrieved from https://citizenlab.org/2013/11/asia-chats-investigating-regionally-based-keyword-censorship-line

Hermida, A. (2010). Twittering the news. Journalism Practice, 4(3), 297-308.

Hermida, A. (2012). Social journalism. In E. Siapera \& A. Veglis (Eds.), The handbook of global online journalism (pp. 309-328). Oxford, UK: Wiley-Blackwell.

Lam, C. (2009). China: Beware of $Q Q$ ! Retrieved from https://advox.globalvoices.org/2009/09/24/ china-be-aware-of-qq/

Lee, K., \& Ho, M.-S. (2014). The Maoming Anti-PX protest of 2014. China Perspectives, 3(33), 33-39. 
Lewis, J. D., \& Weigert, A. (1985). Trust as a social reality. Social Forces, 63(4), 967-985.

Lewis, S. C. (2012). The tension between professional control and open participation. Information, Communication \& Society, 15(6), 836-866.

Lewis, S. C., \& Usher, N. (2013). Open source and journalism. Media, Culture \& Society, 35(5), 602-619.

Lewis, S. C., \& Westlund, O. (2014). Big data and journalism: Epistemology, expertise, economics, and ethics. Digital Journalism, 3(3), 447-466.

Ling, R., \& Campbell, S. W. (Eds.). (2011). Mobile communication. New Brunswick, NJ: Transaction.

Lorenzo-Dus, N., \& Bryan, A. (2011). Recontextualizing participatory journalists' mobile media in British television news: A case study of the live coverage and commemorations of the 2005 London bombings. Discourse and Communication, 5(1), 23-40.

Mabweazara, H. (2011). Between the newsroom and the pub. Journalism, 12(6), 692-707.

Magistad, M. K. (2013). Is Beijing about to pull the plug on two major American news operations in China? Retrieved from https://www.pri.org/stories/2013-12-12/beijing-about-pull-plugtwo-major-american-news-operations-china

Mäkinen, M., \& Kuira, M. W. (2008). Social media and post-election crisis in Kenya. The International Journal of Press/Politics, 13(3), 328-335.

McBride, K., \& Rosenstiel, T. (2014). The new ethics of journalism. Thousand Oaks, CA: CQ Press.

Mills, J., Egglestone, P., Rashid, O., \& Väätäjä, H. (2012). MoJo in action. Continuum, 26(5), 669-683.

Nel, F., \& Westlund, O. (2012). The 4C's of mobile news. Journalism Practice, 6(5-6), 744-753. Nyre, L. (2012). Locative journalism. Convergence, 18(3), 297-314.

Rai, S. (2014, August 25). In India, an app for chats and for keeping secrets. The New York Times. Retrieved from http:/www.nytimes.com/2014/08/26/world/asia/in-india-an-app-for-chatsand-for-keeping-secrets.html

Reich, Z. (2008a). How citizen create news stories. Journalism Studies, 9(5), 739-758.

Reich, Z. (2008b). The roles of communication technology in obtaining news. Journalism \& Mass Communication Quarterly, 85(3), 625-646.

Salo, J., \& Karjaluoto, H. (2007). A conceptual model of trust in the online environment. Online Information Review, 31(5), 604-621.

Schudson, M. (1997). The sociology of news production. In D. Berkowitz (Ed.), Social meanings of news (pp. 7-22). New York, NY: SAGE.

Sigal, L. (1973). Reporters and officials. Washington, DC: DC Health.

Silverman, C. (Ed.). (2014). Verification handbook. Maastricht, the Netherlands: European Journalism Centre.

Tuchman, G. (1972). Objectivity as strategic ritual. American Journal of Sociology, 77(4), 660-679.

Väätäja, H., \& Egglestone, P. (2012, February). Briefing news reporting with mobile assignments. Paper presented at the Conference on Computer Supported Cooperative Work, Seattle, WA.

Weigert, A. (1981). Sociology of everyday life. New York, NY: Longman.

Westlund, O. (2010). New(s) functions for the mobile. New Media \& Society, 12(1), 91-108.

Westlund, O. (2013). Mobile news. Digital Journalism, 1(1), 6-26.

\section{Author biographies}

Valerie Belair-Gagnon is Assistant Professor of Journalism Studies at the Hubbard School of Journalism \& Mass Communication, and Affiliated Faculty in the Department of Sociology at the 
University of Minnesota. She is Director of the Minnesota Journalism Center and Affiliated Fellow at the Yale Information Society Project. Her research interests are in journalism studies, emerging media, social media, innovation, and audience engagement. She is the author of Social Media at BBC News (Routledge, 2015). She tweets at @journoscholar

Colin Agur is Assistant Professor at the Hubbard School of Journalism \& Mass Communication at the University of Minnesota - Twin Cities. His research examines contemporary mobile phone usage, the social and legal implications of mass mobile telephony, and the unanticipated consequences of network development. Regionally, he is interested in India, China and other developing economies, and the United States. He tweets at @ colinagur

Nicholas Frisch is a doctoral student at Yale's East Asian Languages and Literatures program, researching Chinese-language media. He has reported from Asia for the New York Times, The Wall Street Journal, The New Yorker, Columbia Journalism Review, and Foreign Affairs. Nick was a Fulbright Fellow in Beijing, a Blakemore Fellow in Taipei, a visiting fellow at Hong Kong University's Journalism and Media Studies Centre, and a research fellow at Columbia Journalism School. 